\title{
Are Universities to Blame for the IT Careers Crisis?
}

\author{
Glen L. Van Der Vyver and Michael S. Lane \\ University of Southern Queensland \\ Department of Information Systems \\ Toowoomba, Australia
}

vandervy@usq.edu.au lanem@usq.edu.au

\begin{abstract}
At a time when the IT industry in general and the IT academy in particular face major challenges, some accuse universities of producing graduates with poor or inappropriate skills. This qualitative study, based on interviews with fifteen senior IT executives and managers in the Australian financial services industry, examines what employers seek when they recruit new graduates. We find that employers now expect much more from IT graduates. They require a blend of technical, business and people skills combined with the right attitude. Furthermore, requirements are highly mediated by contextual factors such as company size and corporate culture. We also find that universities are not perceived as negatively as some would have it. Universities face a significant challenge in producing graduates with much wider skill sets. Although this study was conducted in Australia, we are of the opinion that the issues discussed are relevant in the wider international context.
\end{abstract}

Keywords: IT Education; skills crisis; graduate employment; outsourcing; graduate attributes

\section{Introduction}

As is the case throughout the developed world, these are troubled times for the Information Technology profession in Australia. For IT academics, the situation has degenerated markedly in the last 18 months and now threatens to take on crisis proportions. Restructuring and retrenchment, which would have been unthinkable a few years ago, have besieged the IT academy and there is little to indicate that the worst is not yet to come.

Unfortunately, there are those within the profession who choose to ignore or obfuscate the real and apparent causes of the crisis and choose to blame IT academics for causing some (or most) of the problem. The common cry of these people is that the jobs are out there but the IT departments at Australian universities are simply not producing candidates with the correct skills. This cry is

Material published as part of this publication, either on-line or in print, is copyrighted by the Informing Science Institute. Permission to make digital or paper copy of part or all of these works for personal or classroom use is granted without fee provided that the copies are not made or distributed for profit or commercial advantage AND that copies 1 ) bear this notice in full and 2) give the full citation on the first page. It is permissible to abstract these works so long as credit is given. To copy in all other cases or to republish or to post on a server or to redistribute to lists requires specific permission and payment of a fee. Contact Publisher@InformingScience.org to request redistribution permission. as likely to come from within the profession as from without and a few of those whose clarion call this has become are themselves academics.

Recently, the national president of the Australian Computer Society issued what amount to a position statement: Our migration and university systems are not producing the skills we need. Both are churning out bulk programmers, who remain oversupplied when we 
really need competent broadly based technology specialists. The lack of such professionals represents a major obstacle to growth ... (The Australian, June 14, 2005, p. 31). The ACS is clearly of the opinion that a new skills crisis is emerging and that universities are part of the problem rather than part of the solution.

This study seeks to critically examine the so-called skills crisis and the quality of graduates produced by Australian universities. We enter the debate with open minds, even conceding that it is possible that the position of the ACS as regards the skill sets which are in demand is fundamentally correct. We interviewed fifteen executives and senior managers in the financial services industry, focusing on graduate attributes. Our point of departure is that one of the most important concerns facing IT academics today is the issue of graduate employment for their students.

\section{The Information Technology Career in Crisis}

Since the end of the dot-com boom, times have been tough for Information Technology professionals (Malykhina, 2004). Smith (2004, p. 1) argues that not only is the job market much tighter but employers are expecting much more. She sums up the situation as follows: Structural changes in the economy have created an employment environment that dictates hiring selectivity in the Information Technology field. Unemployment has soared amongst established professionals and new graduates are finding it difficult to obtain employment in the field (Chabrow, 2003; Chen, 2003). Trends in outsourcing, offshoring, migration and the continued demands on corporations to cut costs suggest that things are likely to get worse before they get better, if indeed they ever do (Fang, Lee, Lee \& Huang, 2004). Given the problems faced in areas such as engineering (see below) it is ominous that there are warnings (Costlow, 2003) that the software area is likely to suffer more than most technical areas.

Fang, Lee, Lee, and Huang (2004) conducted an empirical study using IT graduates in the USA and conclude that, in a tight job market, various factors improve the chance of securing a job offer. These include gender, whether an internship was completed and the nature of the internship, double majors, GPA, time of declaration of the major and what type of courses were completed in the major. It is clearly no longer sufficient to simply have completed an IT major. Employers are interested in specific courses and double majors with a business subject. Essentially, employers seem to be seeking a balance between technical, communication and business skills.

Smith (2004) points out that graduates in general, and those who have majored in IT in particular, now face substantial career barriers when attempting to establish themselves in the field. Swanson and Woitke (1997, p. 434) defined career barriers as events or conditions, either within the person or in his or her environment, that make career progress difficult. Career barriers often have a pervasive influence on the process of career choice and establishment. They have a strong influence on cognitive and affective processes and the ultimate choices made by the individual (Swanson, Daniels, \& Tokar, 1996). Career barriers operate insidiously, undermining even the best, most motivated and most confident of students (Albert \& Luzzo, 1999; Brown \& Brooks, 1996). Many students find themselves making decisions based on their perceptions of career barriers and organizations like the ACS hardly instill confidence in potential students with their pronouncements.

Weber (2004) argues that the current downturn in the IT profession is a purge after years of excess: He argues that the dot-com boom was an aberration and what followed was a situation where companies refused to continue investing heavily in IT. In tandem with the wave of downsizing which followed, many jobs moved offshore, particularly to China and India, where there are many highly skilled but cheap IS professionals. Weber also points out that the shock of these events has of necessity had a major influence on people teaching ICT because there is now more capacity than is required. 
Weber identifies five trends which should not be ignored by IT educators, students and practitioners, namely: IT occupations will remain prominent, there will be fluctuations in demand for IT professionals, the IT employment marketplace will be global, change will be rapid, and IT will be the bellwether for other occupations. He urges educators in particular to be open to the needs of the global market, eschew regulation, and design curriculum that delivers skills and knowledge that are resistant to change,

Weber's analysis of the current state of play in IT employment (and IT education) is insightful and penetrating. There are, however, a number of issues which must be addressed. Weber's apparent point of departure is that of a firm believer in economic rationalism and globalization. We argue that his analysis must be viewed in terms of its point of departure and we argue that his vision of unencumbered IT professionals freely roaming the globe in search of job opportunities is perhaps overly optimistic. Clearly, there are many barriers that make this very difficult, for example:

- We are still a very long way from the situation where national labour markets are open to all and sundry. Australians, for example, cannot simply arrive in any foreign country of their choice and apply for IT jobs.

- The salary structures in some countries are so low that it would be impossible for the worker to return home.

- There is immense opportunity cost associated with constant relocation.

- The emotional and social overheads of this type of peripatetic life come at a cost to society and the individual.

The reality of the situation is that jobs move more frequently than people. We argue that the global IT jobs market may better be characterized as one where jobs are continually on the move, seeking cheap (and cheaper) human resources. In our opinion, the greatest strength of Weber's analysis is his detailed advice for a new IT curriculum, which he believes will prepare students for the demands of the new paradigm. Effectively, he recommends that 'softer' skills drive the curriculum but are backed up with 'vocational' courses in the technology of the day. We concur that this is the way forward - teach students fundamental skills but also allow them to hit the ground running. That being said, while there has been much talk about the need for IT graduates to be taught more 'soft' skills, empirical justification for such an approach is tenuous at best and the word 'soft' is often ambiguously defined. So, for example, a recent major study used a content analysis of newspaper advertisements and discovered that recruitment continues to focus on 'hard' skills (Gallivan, Truex \& Kvasny, 2004). We argue that the approach suggested by Weber provides us with a middle way but it could mean that we need to extend the curriculum.

\section{Research Questions and Method}

The two research questions investigated in this interpretative study of graduate attributes are:

- RQ1: What attributes are you looking for in new graduates?

- RQ2: How well are Australian universities preparing IT graduates for the workplace?

The qualitative method of a series of in-depth interviews allowed the researchers to explore and identify the key issues associated an open ended set of research questions in an interpretative manner in line with the research objectives of this study (Miles \& Huberman, 1994; Yin, 1994). 


\section{Data Analysis}

Table 1 shows a summary of the key graduate attributes identified in the analysis of the interview data. For each attribute we note the number of interviewees who mentioned that attribute:

Table 1: Key graduate attributes

\begin{tabular}{|l|l|}
\hline Graduate Attribute & Number of respondents \\
\hline 1. $\quad$ Communication Skills & 10 \\
\hline 2. $\quad$ Understand Business & 10 \\
\hline 3. $\quad$ Work Ethic & 9 \\
\hline 4. $\quad$ Technical Skills & 9 \\
\hline 5. Database & 8 \\
\hline 6. Java & 7 \\
\hline 7. Business Analysis & 7 \\
\hline 8. . Net & 6 \\
\hline 9. Adaptability / Learning & 6 \\
\hline 10. Cultural fit & 5 \\
\hline 11. People Skills & 5 \\
\hline 12. Logic & 5 \\
\hline 13. Adaptability / Learning & 5 \\
\hline 14. Problem solving & 5 \\
\hline 15 Conscientious & 4 \\
\hline 16. Understand Technology & 4 \\
\hline 17. GPA & 4 \\
\hline 18. Honesty & 2 \\
\hline $\begin{array}{l}\text { 19.Leadership } \\
\text { Potential }\end{array}$ & 2 \\
\hline $\begin{array}{l}\text { 20.Proven } \\
\text { Development Skills }\end{array}$ & 2 \\
\hline 21. C++ & 2 \\
\hline 22.Open Source & 1 \\
\hline
\end{tabular}

\section{RQ1: What attributes are you looking for in new graduates?}

We were struck by the number and diversity of attributes which emerged. So-called 'soft' skills have clearly become more important but the overriding impression is that of a graduate who needs to be well-rounded and comfortable in the business and technical arenas. In short, the bar has been raised and employers expect a lot.

The idea of a generalised ideal IT graduate does not exist. Ideal graduate types varied significantly by organization type. An interviewee from a medium-sized company which develops software and offers outsourcing services offers the follow vision: 
The old technological requirements are out ... The Business Analysts are the IT guns ... they need to be good communicators, understand current technology and business . . and, they need to leverage technological skills.

It is interesting to note that in a company which values flair, creativity and people skills the ability to leverage technological skills is still important. This company is not looking for technological illiterates. An interviewee from a smaller software house with a similar profile and values takes up the argument:

We rarely hire people on technological skills. . . We rate people and business skills and want team players who fit in

At the other extreme, one outsourcing vendor prefers to employ engineering graduates because they value structure and very strong technical skills. The interviewee mentioned softer skills almost in passing. An interviewee from a financial institution which does a lot of development inhouse has the following perspective:

I look for technically capable people, for example .Net, Java, $C^{++}$,Oracle who can make a business case. I want front-end and back-end skills from requirements analysis to coding. I like to see proven development skills...

An interviewee from another outsourcing vendor takes a similar approach:

The work is varied . . some of it legacy. We need highly specialised technical skills for a lot of it. We look for people who are logical ... problem solvers ... who can debug . . . everything from UNIX scripts to .Net and Java.

We found that larger, more formalised organizations placed more emphasis on technical skills while smaller, decentralised organizations valued softer skills more highly. The majority of organizations value both sets of skills, however. One interviewee chose identified the three skill sets, in order of importance:

- Technical Skills.

- Business Skills.

- A realistic outlook on life.

Several other interviewees would have broadly agreed with this but might have changed around the order of importance. Most of the interviewees favoured a balanced set of hard and soft skill while a few tended to the extremes.

\section{RQ2: How well are Australian universities preparing IT graduates for the workplace?}

In many cases this question naturally progressed into a broader discussion of problems that have been experienced with IT graduates. We found little evidence of a sense of deep dissatisfaction with the quality of graduates emerging from Australian universities. On the other hand, it is undeniable that there are issues which must be addressed but it is our conviction that many of these issues are perennial.

A number of interviewees identified attitude as a key problem, for example:

What we need is people who understand the meaning of $R-C=P / L$, i.e. Revenue - Cost $=$ Profit or Loss ... Too many graduates sit around and wait for things to happen .. they don't understand the costs of keeping them in their seats .. they are not proactive.

Several interviewees were critical of the general communication skills of IT graduates, for example: 
A lot of these people can't write a decent note ... forget about a report ... and presentation skills ... well! But I have a feeling this applies to people from other areas as well.

A relatively common theme was the problems associated with recruiting graduates with the correct combination of attitudes, technical skills and business skills:

Good A/P's are hard to find ... it tends to be one or the other, strong tecchy or strong analyst ... yes, I suppose this is not new ... in my day it was the same.

A few interviewees spoke of a reticence to hire graduates because of the time lag before they were productive, for example:

Recruitment mistakes are expensive ... we want to hire people with proven development skills who understand the SDLC. We hire analyst / programmers who can take on a variety of roles . . (from) requirements analysis to coding.

Although these interviewees were the most critical of the level of expertise of graduates and had the least positive views of the quality of Australian IT graduates, we are not dealing with attitudes which have emerged recently. For decades, employers have wanted graduates who are ready to take on the most complex of projects with no training and for all that time universities have pointed out that they can only do so much. Even where the university has a capstone project course it cannot replicate the environment of a real project. There are certain skills that can only be learned in the workplace.

The majority of interviewees felt that Australian universities were doing a reasonably good job in terms of turning out decent IT graduates. Indeed, several interviewees who are involved in offshoring commented that the quality of Australian IT staff was significantly higher than that of the offshore staff. In some cases, this disparity had so dissipated the perceived cost advantages that work was coming back onshore:

We offshore lower skilled work ... they are not as good as the locals ... a lot of it has come back ... and when it comes to understanding the business and there's obviously no comparison.

We must concede that this viewpoint was by no means universal. While it was widely acknowledged that the quality of Australian staff was highly competitive some of the interviewees felt that cost imperatives would drive the lower skilled jobs offshore. One respondent presented a somewhat apocalyptic viewpoint:

There is a tidal wave of offshoring to come. Even if I have a small job, say $\$ 100$, I send it off to India late afternoon and the code is waiting for me in the morning. Sure, standards can be variable but the key is specification. No Australian programmer can compete on cost.

There was no indication amongst interviewees that they thought the IT academy is responsible for the current problems graduates are experiencing in finding work. Rather, the problems are rooted in structural changes associated with the dot com bust, new economic imperatives, and offshoring.

\section{Conclusions and Implications}

Australian companies require adaptable IT staff with a wide range of skills. Although 'soft' skills are much more important than was the case even a few years ago, there is little evidence of the extinction of demand for technical skills. Indeed, the ideal IT employee would offer the company a blend of technical, business and personal skills.

Our study once again exposes some of the dangers of 'survey aggregation'. We argue that there is no such thing as the ideal IT graduate. Requirements are highly contextualised and vary by type and size of company, corporate culture, project type, whether outsourcing is prevalent and a host 
of other factors. The methodology employed in this study has limitations of its own, of course, and we concede that the fact we interviewed fifteen people from one sector (financial services) does raise the issue of generalizability.

We note that there was little mention of skills which are often touted by those who argue that there are too many technical, programming courses in the curriculum. These people frequently favor programs which produce systems integrators and ERP specialists, neither of which was mentioned by the interviewees. This does not surprise us because we argue that it is difficult to produce good systems integrators who do not have a good technical and business background. Furthermore, these types of skills are best learned on the job and grow with experience.

Although there may be scope for improvement, we argue that Australian universities are doing a reasonable job in producing good quality IT staff. Given the constraints imposed upon universities in recent years, they are adapting well to the changed requirements. Universities face signifi-

cant challenges in that they are now asked to produce IT graduates with a far wider range of skills at a time when there are severe pressures to cut costs and constrain curricula. It is a difficult task indeed to produce a graduate who is technically strong, a good communicator, and a savvy businessperson with the right attitudes and values. Indeed, some of these desirables are probably not within the domain of what people can reasonably expect universities to produce.

We do not claim this study is in any way definitive and we readily acknowledge that our information comes from a small number of people operating in a specific industry. We acknowledge that that this study may not be generalizable but we argue that the results are sufficient to stimulate debate about the claims of some that the failure of Australian universities to produce graduates with the correct skills is a key reason for the problems faced in the Australian IT sector.

In conclusion, based on the information obtained in this study, we find that there is much to support Weber's vision of an IT professional who is multi-skilled, flexible and adaptable but less to support the ACS vision of an academy wholly out of touch with the realities of the marketplace.

\section{References}

Albert, K. A., \& Luzzo, D. A. (1999). The role of perceived barriers in career development: A social cognitive perspective. Journal of Counselling and Development, 77(4), 431-436.

Brown, D. \& Brooks, L. (1996). Career choice and development. San Francisco: Josey-Bass.

Chabrow, E. (2004). Fewer IT workers standing in the unemployment line. Information Week, 943, 16.

Chen, C. (2003). Grads aren’t seeing green. Fortune, 147(13), 29.

Costlow, T. (2003). Globalization drives changes in software careers. IEEE Software, 20(8), 14-16.

Fang, X., Lee, S., Lee, T. \& Huang, W. (2004). Critical factors affecting job offers for new MIS graduates. Journal of Information Systems Education, 15(2), 189-204.

Gallivan, M. J., Truex, D. P. \& Kvasny, L. (2004). Changing patterns in IT skill sets 1988-2003: A content analysis of classified advertising. DATA BASE for Advances in Information Systems, 35(3), 65-87.

Malykhina, E. (2004, April 19). IT job market causes concern. InformationWeek, 985, 76.

Miles, MB \& Huberman. (1994), Qualitative data analysis: An expanded sourcebook. Thousand Oaks, CA: Sage Publications.

Smith, S. (2004). Career barriers among information technology undergraduate majors. Information Technology, Learning and Performance Journal, 22(1), 49-57.

Weber, R. (2004). Some implications of the Year-2000 era, dot-com era and offshoring for information systems pedagogy. MIS Quarterly, 28(2), iii-xi. 
Yin, R. K. (1994). Case study research: Design and methods (2nd ed., vol. 5 of 14 vols). Thousand Oaks, CA: Applied Social Research Methods Series, Sage Publications.

\section{Biographies}

Glen Van Der Vyver is a senior lecturer in Information Systems at the University of Southern Queensland. He worked at the 'coalface'in Human Resources and IT (mostly) for around fifteen years before becoming an academic some years ago. Glen teaches primarily in the database area and is currently working on research relating to IT careers, outsourcing, offshoring, the function of the CIO and risk perception.

Michael Lane is a lecturer in the Division of Information Systems, Faculty of Business, University of Southern Queensland. He holds an Honours in Information Technology and a PhD with a focus in E-Commerce Development. He has published widely in Information Systems and Electronic Commerce but has varied interests in research and teaching including outsourcing, corporate governance and the function of the CIO. He has run a postgraduate course on E-Business Strategy at the Australian Graduate School of Business at USQ for the last four years. 